\title{
Ensayo pictórico: Diagnóstico diferencial radiológico en Esclerosis Múltiple
}

Eduardo Peñailillo Toledo', Mario Zerega Ruiz ${ }^{2}$, Elizabeth Guerrero Cornejo², Ethel Ciampi Díaz ${ }^{3}$, Reinaldo Uribe San Martín ${ }^{4}$, Claudia Cárcamo Rodríguez ${ }^{5}$, Leonardo Arraño Carrasco ${ }^{6}$, Sebastián Bravo Grau ${ }^{7}$ Juan Pablo Cruz Quiroga ${ }^{8}$.

1. Residente de Radiología. Departamento de Radiología. Unidad de Neurorradiología. Facultad de Medicina. Hospital Clínico de la Pontificia Universidad Católica de Chile. Santiago, Chile.

2. Fellow de Neurorradiología Diagnóstica. Departamento de Radiología. Unidad de Neurorradiología. Facultad de Medicina. Hospital Clínico de la Pontificia Universidad Católica de Chile.Santiago, Chile.

3. Neuróloga. Centro de Esclerosis Múltiple. Departamento de Neurología. Facultad de Medicina. Hospital Clínico de la Pontificia Universidad Católica de Chile. Santiago, Chile.

4. Neurólogo. Profesor Asistente. Departamento de Radiología. Unidad de Neurorradiología. Facultad de Medicina. Hospital Clínico de la Pontificia Universidad Católica de Chile. Santiago, Chile.

5. Neuróloga. Profesor Asistente Adjunto. Departamento de Radiología. Unidad de Neurorradiología. Facultad de Medicina. Hospital Clínico de la Pontificia Universidad Católica de Chile. Santiago, Chile.

6. Neurorradiólogo. Departamento de Radiología. Unidad de Neurorradiología. Facultad de Medicina. Hospital Clínico de la Pontificia Universidad Católica de Chile. Santiago, Chile.

7. Neurorradiólogo. Departamento de Radiología. Unidad de Neurorradiología. Facultad de Medicina. Hospital Clínico de la Pontificia Universidad Católica de Chile. Santiago, Chile.

8. Neurorradiólogo. Profesor Asistente. Departamento de Radiología. Unidad de Neurorradiología. Facultad de Medicina. Hospital Clínico de la Pontificia Universidad Católica de Chile. Santiago, Chile.

\section{Pictory essay: Radiological differential diagnosis of multiple sclerosis}

Resumen: La esclerosis multiple (EM) es la enfermedad inflamatorio-desmielinizante del Sistema nervioso central más prevalente en adultos. La resonancia magnética (RM) juega un rol cada vez más importante en el estudio de esta patología, en especial en su diagnóstico precoz, por lo que la diferenciación imagenológica de variantes frecuentes e infrecuentes de EM con otras patologías de sustancia blanca que comprometen encéfalo y médula espinal es esencial. Mediante una revisión pictórica se ilustrarán características típicas en RM del compromiso por EM y de variantes menos habituales de lesión desmielinizante, y se ilustrarán hallazgos característicos de lesiones relacionadas a vasculopatías inflamatorias y no inflamatorias, encefalomielitis diseminada aguda (ADEM), neuromielitis óptica (NMO) y enfermedades vasculares de la médula espinal que pueden simular EM, con énfasis en el diagnóstico diferencial radiológico.

Palabras clave: CADASIL, Encefalomielitis diseminada aguda, Enfermedades desmielinizantes, Esclerosis múltiple, Neuromielitis óptica, Síndrome de Susac.

Abstract: Multiple sclerosis (MS) is the most prevalent inflammatory-demyelinating disease of the central nervous system in adult population. Magnetic resonance imaging (MRI) has an increasingly important role, especially in early diagnosis, so the imaging differentiation of frequent and infrequent variants of MS with other white matter diseases of brain and spinal cord is essential. Through a pictorial essay we show typical $M R$ features of MS and more infrequent variants of demyelinating lesions and illustrate characteristic imaging findings of inflammatory and non-inflammatory vasculopathies, acute disseminated encephalomyelitis (ADEM), neuromyelitis optica (NMO) and vascular diseases of spinal cord that may simulate MS, with emphasis on imaging differential diagnosis.

Keywords: Acute disseminated encephalomyelitis, CADASIL, Demyelinating diseases, Multiple sclerosis, Neuromyelitis optica, Susac syndrome.

Peñailillo E, et al. Ensayo pictórico: Diagnóstico diferencial radiológico en Esclerosis Múltiple. Rev Chil Radiol 2019; 25(1): 05-18.

${ }^{\star}$ Correo electrónico: Juan Pablo Cruz Quiroga / jpcruz81@gmail.com

Trabajo enviado el 07 de diciembre de 2018. Aceptado para publicación el 05 de marzo de 2019. 


\section{Introducción}

La esclerosis múltiple (EM) es la enfermedad inflamatorio-desmielinizante crónica del sistema nervioso central más prevalente en adultos, afectando a más de 2 millones de personas alrededor del mundo, con un curso variable que finalmente resulta en alta morbilidad para los pacientes y costo para el sistema de salud ${ }^{(1)}$. El estudio con resonancia magnética (RM) juega un rol cada vez más importante en la práctica clínica, permitiendo un diagnóstico precoz y más certero, posibilitando la monitorización de respuesta a terapias, además de contribuir al conocimiento de la fisiopatología de la enfermedad y la evaluación de nuevos tratamientos ${ }^{(2)}$. La EM tiene manifestaciones típicas en imágenes que se encuentran incluidas en los criterios diagnósticos de la enfermedad (Tabla 1$)^{(3)}$. No obstante, existen variantes menos habituales que, sumado al gran número de otras patologías de sustancia blanca de diversas etiologías, pueden presentar una dificultad diagnóstica. Por tanto, es necesario estar familiarizado con aspectos imagenológicos menos frecuentes de lesiones desmielinizantes en EM y las características de otras patologías de sustancia blanca para realizar un correcto diagnóstico diferencial. El objetivo de esta revisión pictórica es ilustrar el aspecto imagenológico típico de las placas desmielinzantes en EM, realizar una descripción de variantes menos habituales de lesión desmielinizante y caracterizar imagenológicamente las lesiones relacionadas a vasculopatías inflamatorias y no inflamatorias, encefalomielitis diseminada aguda (ADEM), neuromielitis óptica (NMO) y enfermedades vasculares de la médula espinal que pueden simular EM, con énfasis en el diagnóstico diferencial.

\section{Aspecto típico de las lesiones desmielinizantes en EM}

Las lesiones desmielinizantes características en EM típicamente comprometen la sustancia blanca periventricular con lesiones ovoídeas perpendiculares a los ventrículos (dedos de Dawson) involucrando la interfase calloso-septal, las fibras $U$ de asociación corta cuando son yuxtacorticales, sustancia blanca periventricular y sustancia blanca de fosa posterior en situación periférica o periventricular pero no central y con tendencia a seguir el trayecto de pares craneanos (Figura 1a-1d). En la médula espinal el compromiso es típicamente parcial en el plano transversal, dorsal o lateral siguiendo el trayecto de las venas de drenaje, y de extensión longitudinal corta, sin o con leve edema medular en la fase aguda (Figura 2)(4). Estas lesiones son hiperintensas en T2/FLAIR, pueden presentar baja señal en T1 en el caso de corresponder a lesiones crónicas y, de presentar realce con medio de contraste, pueden tener un realce en anillo abierto característico de lesión desmielinizante (Figura $1 e)^{(5,6)}$. Pueden tener restricción a la difusión
Tabla 1. Terminología utilizada en criterios diagnósticos de EM utilizando RM.

\begin{tabular}{|c|c|}
\hline Término & Definición \\
\hline Lesión & $\begin{array}{l}\text { Área de hiperintensidad en T2 o DP de } \\
\text { al menos } 3 \mathrm{~mm} \text { en su eje largo. }\end{array}$ \\
\hline $\begin{array}{l}\text { Lesión } \\
\text { yuxtacortical }\end{array}$ & $\begin{array}{l}\text { Lesión de sustancia blanca que contacta } \\
\text { la corteza, no separada por sustancia } \\
\text { blanca normal. }\end{array}$ \\
\hline $\begin{array}{l}\text { Lesión } \\
\text { periventricular }\end{array}$ & $\begin{array}{l}\text { Lesión de sustancia blanca que contacta } \\
\text { los ventrículos sin sustancia blanca } \\
\text { sana que la separe, incluyendo lesiones } \\
\text { encuerpo calloso, con exclusión de } \\
\text { lesiones en sustancia gris profunda. }\end{array}$ \\
\hline $\begin{array}{l}\text { Lesión } \\
\text { infratentorial }\end{array}$ & $\begin{array}{l}\text { Lesión en troncoencéfalo (típicamente } \\
\text { superficial), pedúnculos cerebelosos } \\
\text { o cerebelo. }\end{array}$ \\
\hline Lesión espinal & $\begin{array}{l}\text { Lesión cervical, torácica o lumbar } \\
\text { visible hiperintensa en T2 y STIR, DP } \\
\text { u otra secuencia apropiada, o en } 2 \\
\text { planos en T2 }\end{array}$ \\
\hline Lesión cortical & $\begin{array}{l}\text { Lesiones en el espesor de la corteza, } \\
\text { primariamente leucocorticales, rara } \\
\text { vez subpiales. Usualmente se requiere } \\
\text { de secuencias especiales como DIR, } \\
\text { PSIR o MP-RAGE. Distinguir de arte } \\
\text { factos. }\end{array}$ \\
\hline $\begin{array}{l}\text { Criterios de } \mathrm{McD} \\
\text { y diseminación }\end{array}$ & $\begin{array}{l}\text { onald para diseminación en tiempo (DIT) } \\
\text { en espacio (DIS) demostrada por RM. }\end{array}$ \\
\hline DIS & $\begin{array}{l}\geq 1 \text { lesión(es) característica(s), en } \geq 2 \\
\text { de las cuatro áreas del SNC: periven } \\
\text { tricular, cortical o yuxtacortical, encéfalo } \\
\text { infratentorial, médula espinal, sean } \\
\text { lesiones sintomáticas o no. }\end{array}$ \\
\hline DIT & $\begin{array}{l}\text { Presencia simultánea de lesiones que } \\
\text { realzan y no realzan con gadolinio en } \\
\text { cualquier momento, o nueva lesión } \\
\text { hiperintensa en T2 o que realce con } \\
\text { gadolinio en RM de seguimiento, res } \\
\text { pecto al basal, independiente del tiempo } \\
\text { transcurrido. }\end{array}$ \\
\hline \multicolumn{2}{|c|}{$\begin{array}{l}\text { Adaptado de Thompson AJ, Banwell BL, Barkhof F, Carroll } \\
\text { WM, Coetzee T, Comi G, et al. Diagnosis of multiple sclerosis: } \\
2017 \text { revisions of the McDonald criteria. Lancet Neurol. 2018; } \\
\text { 17(2): } 162-173 \text {. } \\
\text { DP: densidad protónica. } \\
\text { STIR: short tau inversion recovery. } \\
\text { DIR: double inversion recovery. } \\
\text { PSIR: phase-sensitive inversion recovery. } \\
\text { MP-RAGE: magnetization-prepared rapid acquisition with } \\
\text { gradient echo. }\end{array}$} \\
\hline
\end{tabular}



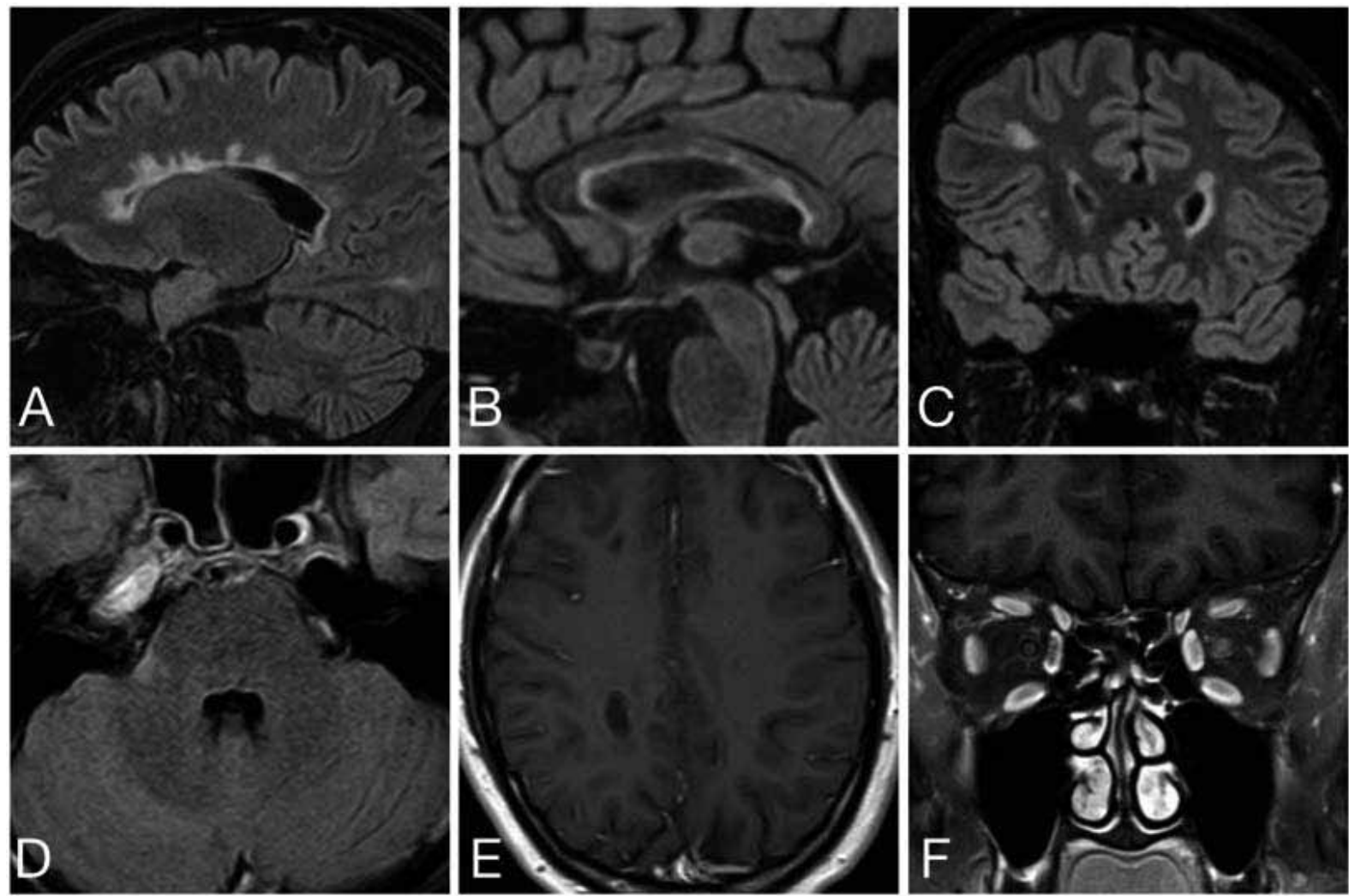

Figura 1: Compromiso típico por EM - RM. FLAIR sagital (a-b), coronal (c) y axial (d) donde se demuestran lesiones hipertensas periventriculares (a), de la interfase calloso septal (b), yuxtacortical (c) y pontina excéntrica (d). T1 con contraste axial (e) donde se evidencia realce en anillo abierto típico de lesión desmielinizante. T1 con saturación grasa post contraste coronal (f) donde se observa realce inflamatorio del nervio óptico izquierdo.
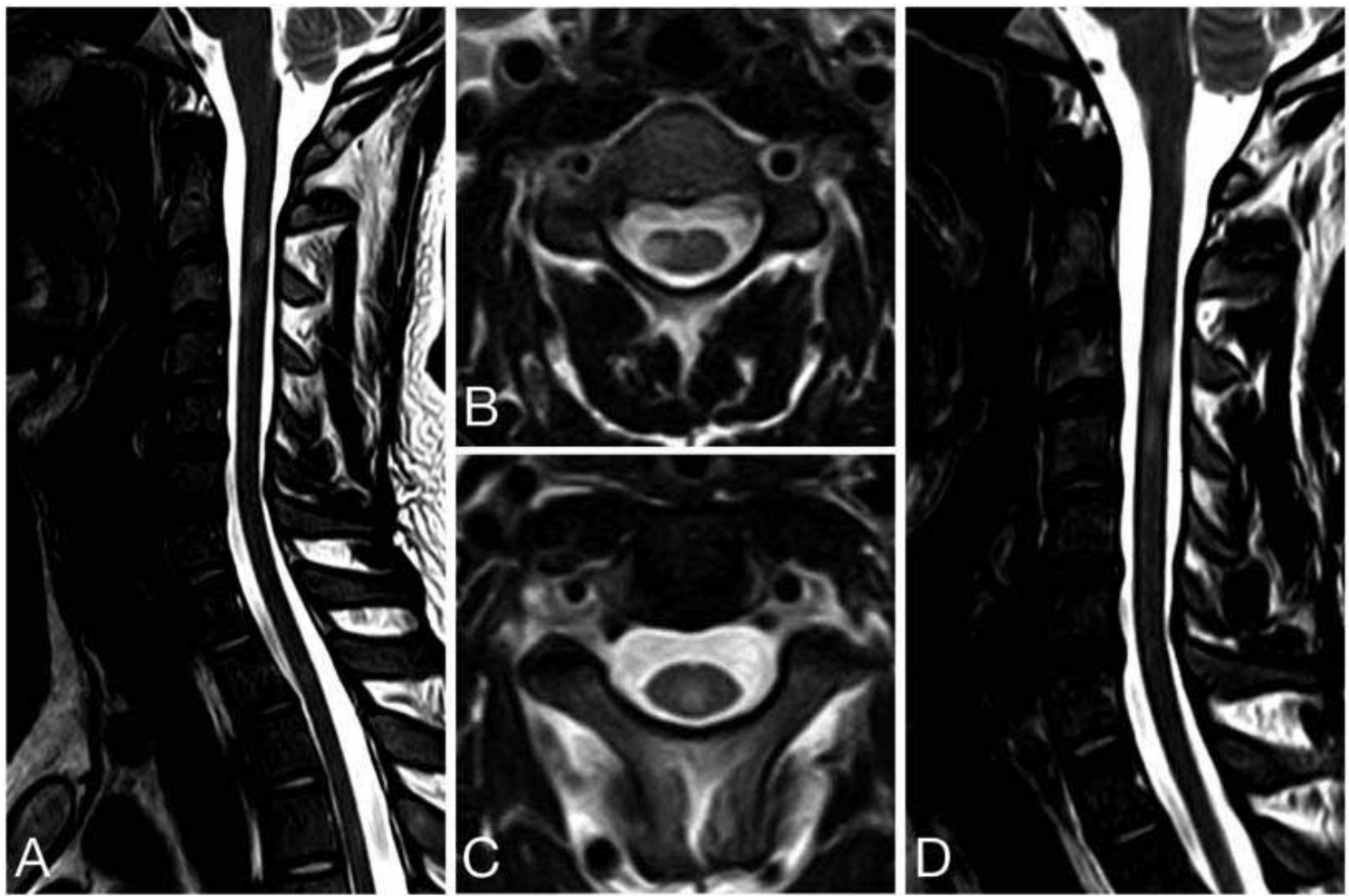

Figura 2: Aspecto típico de compromiso medular en EM - RM. T2 sagital (a) y axial (b) donde se observa una lesión hipertensa semegmentaria corta a nivel C2-C3, con compromiso parcial en el plano transversal. T2 axial (c) y sagital (d) en otro paciente donde se observan al menos dos lesiones a nivel C3 y C4 de similares características. 
en forma periférica y ocasionalmente es visible una vena central. En el caso de presentar neuritis óptica esta suele ser unilateral y comprometer menos del $50 \%$ de la extensión del nervio óptico.

\section{Variantes menos típicas de lesión desmielinizante}

Desmielinización tumefacta. Corresponde a una lesión inflamatoria mayor de $2 \mathrm{~cm}$ con edema y efecto de masa, pudiendo simular una neoplasia(7). Habitualmente se trata de lesiones solitarias con un pronóstico favorable y buena respuesta a corticoides. Su patogenia es mal comprendida, se cree que pudiesen representar un espectro focal de ADEM y, aunque la mayoría no progresa a EM, puede tratarse de un primer evento de esta enfermedad por lo que se sugiere seguimiento clínico radiológico. En imágenes se observa una lesión hiperintensa en T2/FLAIR en la sustancia blanca con pequeñas venas transmedulares hipointensas en T2 en el centro, con realce anular abierto y restricción en la periferia, con compromiso de las fibras $U$ y respeto cortical. La ausencia del desplazamiento de estructuras vasculares es un signo útil para distinguirla de patología neoplásica (Figura 3) $^{(8,9)}$.

Esclerosis concéntrica de Baló. Si bien inicialmente fue considerada como una enfermedad aparte, de mal pronóstico, en la actualidad se considera un patrón morfológico - radiológico infrecuente pero característico de lesión desmielinizante más que una entidad nosológica en particular, pudiendo estar presente en distintas enfermedades desmielinizantes como EM, ADEM, NMO y otros. Su prevalencia es desconocida y predomina en hombres y pacientes jóvenes. La presentación clínica varía según la localización. En tomografía computada (TC) se presenta como una lesión única hipodensa con centro más denso y en RM como una lesión hiperintensa en FLAIR con un anillo interno y otro externo de restricción en difusión (Figura 4$)^{(9,10)}$. Si se presenta como lesión única tiene alta probabilidad de corresponder a un evento desmielinizante aislado y monofasico, sin embargo, en el caso de ser múltiples tiene alta probabilidad de tratarse de una esclerosis múltple que requiere seguimiento y tratamiento como tal.
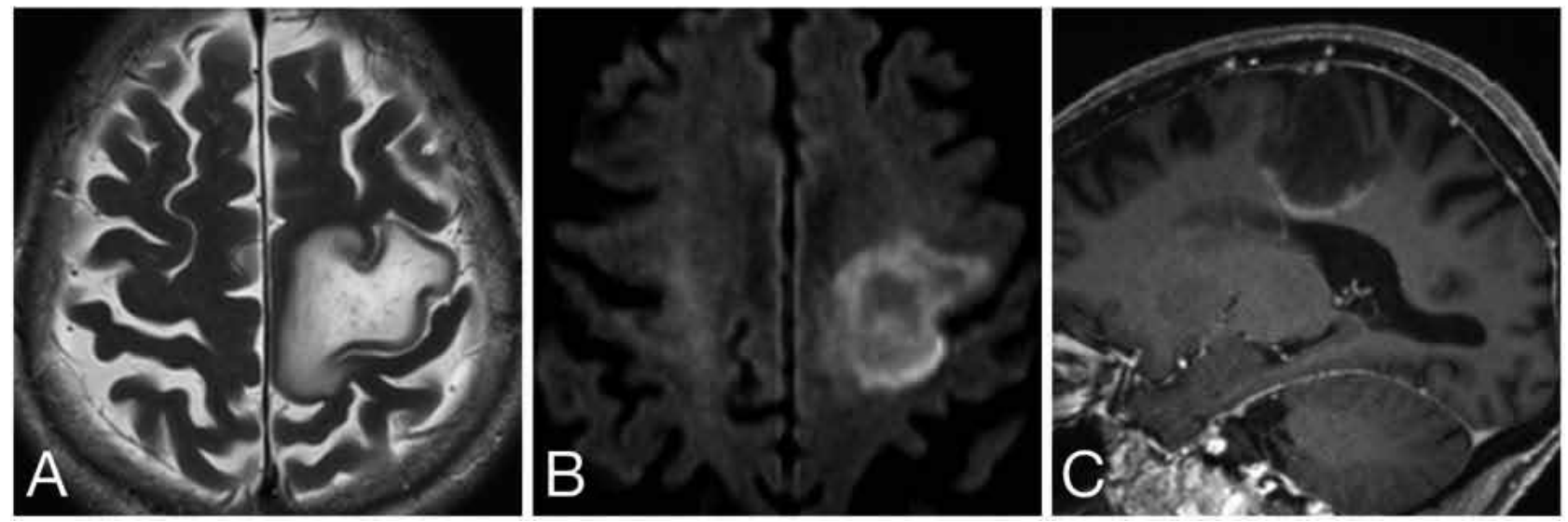

Figura 3: Desmielinización tumefacta - RM. T2 axial (a), difusión isotrópica $b=1000$ axial (b) y T1 eco gradiente con contraste sagital (c) donde se observa una lesión hipertensa en T2 frontal izquierda con pequeños focos hipointensos en su interior, con restricción periferia en la difusión y realce anular abierto.

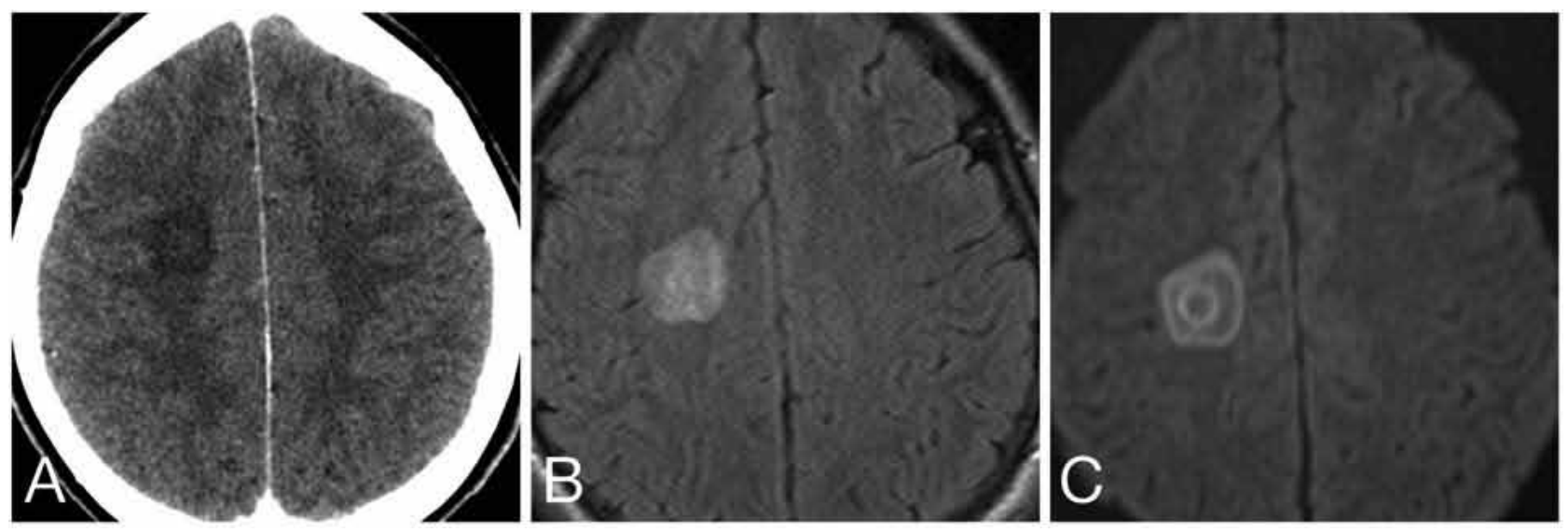

Figura 4: Esclerosis concéntrica de Baló - TC - RM. TC axial (a) muestra una lesión única hipodensa de centro más denso. FLAIR (b) y difusión isotrópica $b=1000$ axial (c) evidencia una lesión única hipertensa con doble anillo de restricción en difusión. 
Enfermedad de Schilder. También llamada esclerosis mielinoclástica difusa, provoca extensas áreas confluentes bilaterales de desmielinización, también con compromiso de tronco y cerebelo (Figura 5). Es muy infrecuente, usualmente se presenta en niños, con rápida progresión de la enfermedad en 1 a 2 años, pero puede ser fulminante. Dentro del diagnóstico diferencial se debe descartar primero una adrenoleucodistrofia ligada al X, que puede presentar características imagenológicas indiferenciables ${ }^{(7,9)}$.
Enfermedad de Marburg. Patología infrecuente, corresponde a una presentación agresiva de EM de predominio en pacientes jóvenes. Presenta una rápida progresión con alta carga lesional y curso fulminante. Puede también constituir un evento terminal en una EM clásica. Se presenta con múltiples lesiones confluentes en sustancia blanca supra e infratentorial, con edema y realce puntiforme con contraste (Figura 6). Puede simular una ADEM, pero se diferencia en la ausencia de compromiso de sustancia gris profunda
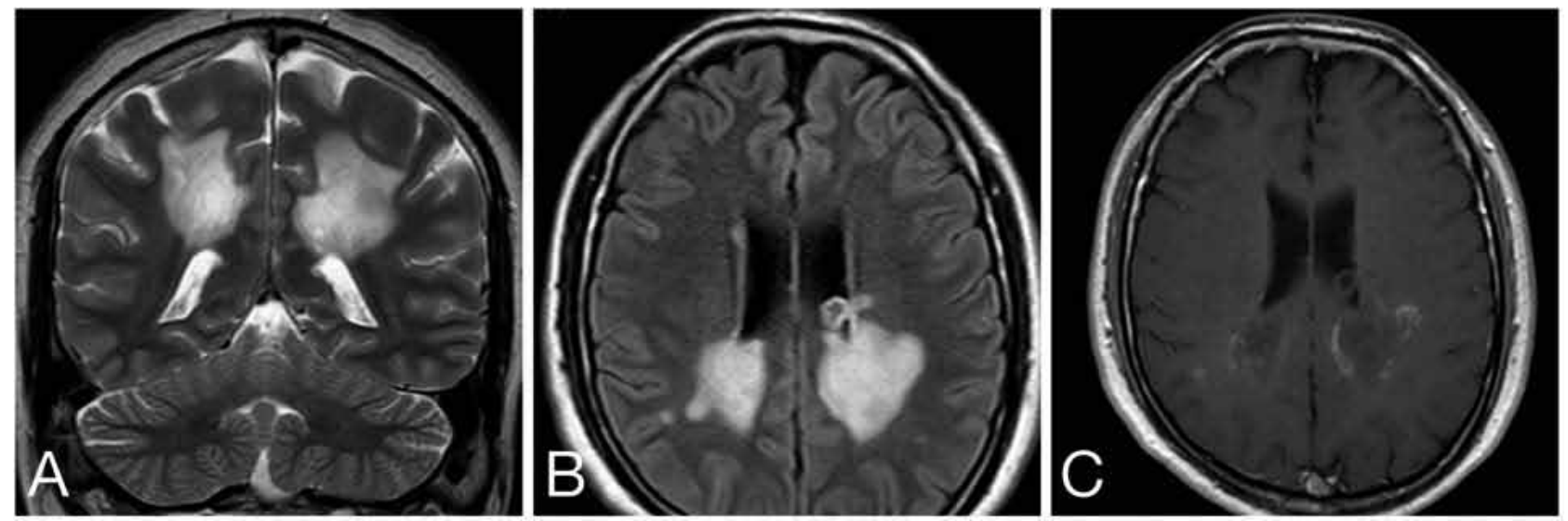

Figura 5: Enfermedad de Schilder - RM. T2 coronal (a), FLAIR axial (b) y T1 con contraste axial (c) donde se observan lesiones confluentes en sustancia blanca parietal periventricular bilateral, con realce anular abierto típico de lesión desmielinizante.
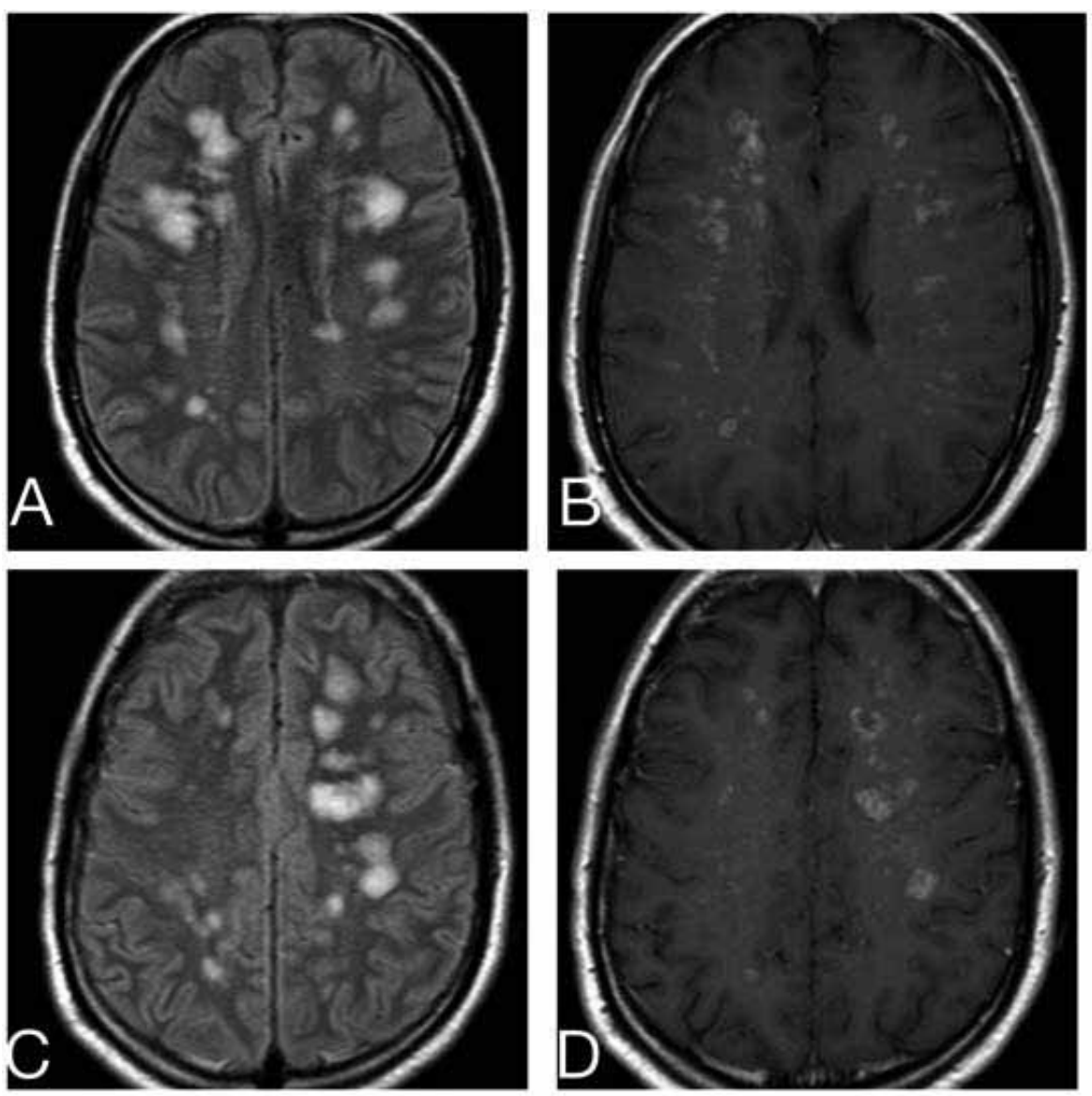

Figura 6: Enfermedad de Marburg - RM. FLAIR axiales (a,c) y T1 axial con contraste $(b, d)$ que demuestra múltiples lesiones confluentes en sustancia blanca supratentorial, con realce con gadolinio. No había evidencias de compromiso de sustancia gris profunda (no mostrado). 
y en la presencia de lesiones secuelares ${ }^{(7,9)}$. Cuando los pacientes se tratan en forma precoz y de manera agresiva pueden evolucionar como una EM habitual.

\section{Lesiones relacionadas a enfermedad de vaso pequeño}

Frecuentemente se detectan focos de hiperintensidad en T2/FLAIR de la sustancia blanca supra e infratentorial en estudios realizados por diversos motivos. Estos focos carecen de especificidad y se cree que están explicados por isquemia microvascular. En general se encuentran en pacientes asintomáticos, pero pueden presentarse en pacientes con migraña u otras patologías sistémicas. Es importante la distinción con EM, por la implicancias pronósticas y terapéuticas que tiene y para evitar estudio y seguimiento innecesario. Clínicamente, las lesiones por enfermedad de vaso pequeño se presentan en general en pacientes mayores de 50 años, con factores de riesgo cardiovascular o antecedentes de migraña, en contraste a la EM que se presenta en pacientes jóvenes. Imagenológicamente, el daño microvascular no presenta compromiso de la interfase calloso-septal ni de las fibras $U$ y en caso de compromiso pontino este es profundo, central y con respeto del puente dorsal (Figura 7), a diferencia de EM que lo compromete en forma superficial. Además, puede coexistir con otros hallazgos como microhemorragias o infartos lacunares ${ }^{(11)}$. Este es el diagnóstico diferencial y causa de error mas frecuente en mayores de 50 años.

Existen, no obstante, arteriopatías inflamatorias y no inflamatorias que van a presentar cambios mi- crovasculares a temprana edad, pero con particularidades en la presentación clínica e imagenológica que permiten orientar el diagnóstico.

Enfermedades genéticas de pequeño vaso. Existen varias vasculopatías de vaso pequeño de causa genética y su número probablemente vaya en aumento. La arteriopatía cerebral autosómica dominante con infartos subcorticales y leucoencefalopatía, llamada CADASIL por sus siglas en inglés, corresponde a la enfermedad más conocida de este grupo y la que presenta un patrón característico en imágenes. Es una microvasculopatía hereditaria no inflamatoria producida por la mutación del gen $\mathrm{NOTCH}-3$, lo que resulta en engrosamiento fibrótico de las membranas basales de pequeños vasos. El estudio histopatológico de piel, músculo o cerebro demostrará acumulación de proteína NOTCH-3 y depósito de material osmiofílico granular (GOM). Se presenta en pacientes jóvenes con cefaleas tipo migraña, eventos tipo stroke y demencia precoz. En RM se observan lesiones de sustancia blanca confluentes bilaterales, aunque en casos iniciales se observa compromiso predominante del polo temporal, hallazgo altamente sensible y específico ${ }^{(12)}$ y cápsula externa, con respeto relativo subcortical occipital y orbitofrontal, de corteza y de fibras U (Figura 8). Pueden observarse lesiones en tálamo, ganglios de la base y puente además de microhemorragias e infartos subcorticales. La angiografía presenta una alta tasa de complicaciones en estos pacientes y un escaso rendimiento, por lo que no debiera usarse en el proceso diagnóstico. El tratamiento es básicamente
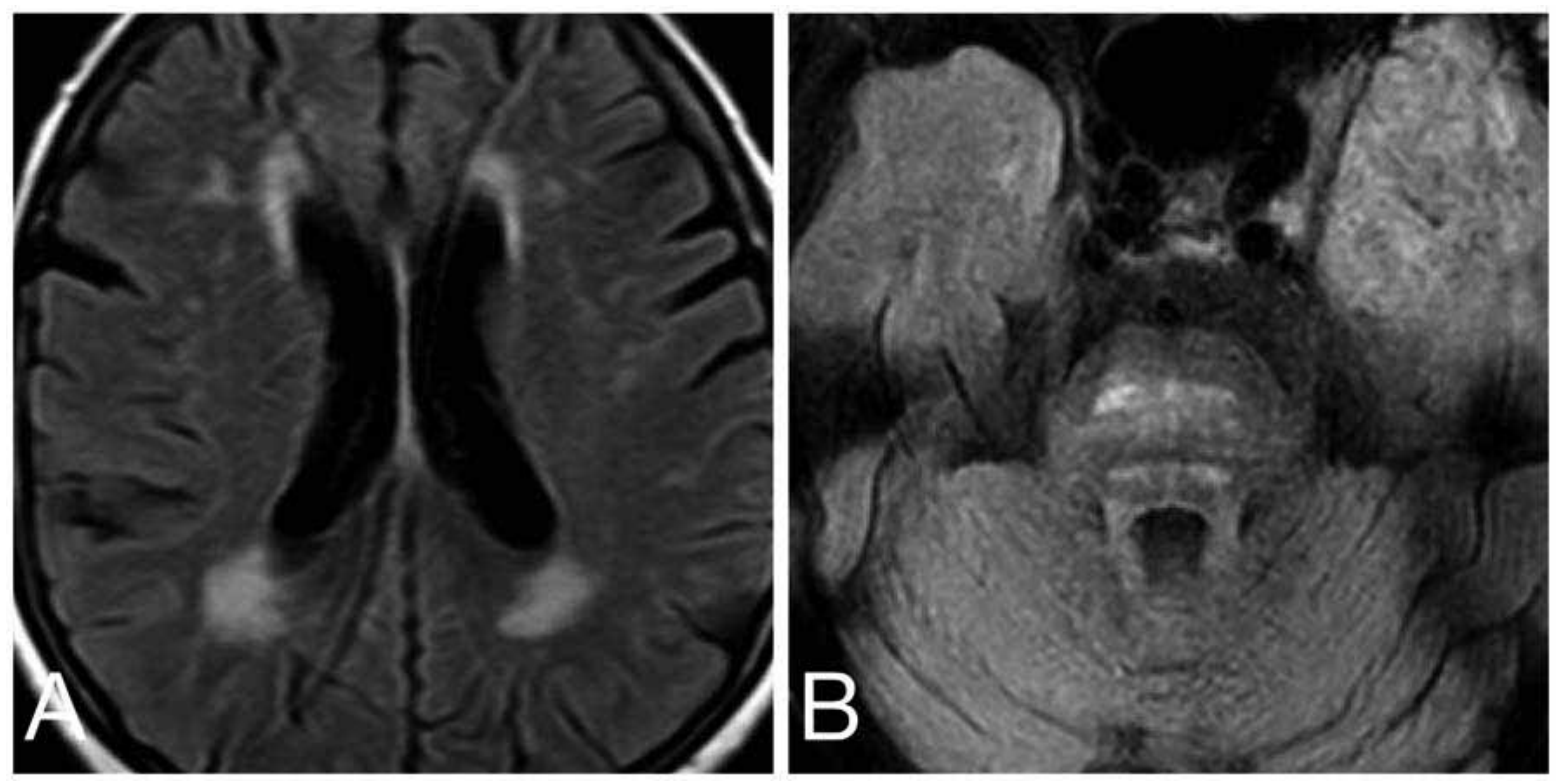

Figura 7: Daño vascular - RM. FLAIR axiales supra (a) e infratentorial (b) muestra focos de alteración de señal subcortical y periventricular sin compromiso de fibras $U$, y con compromiso central del puente. 

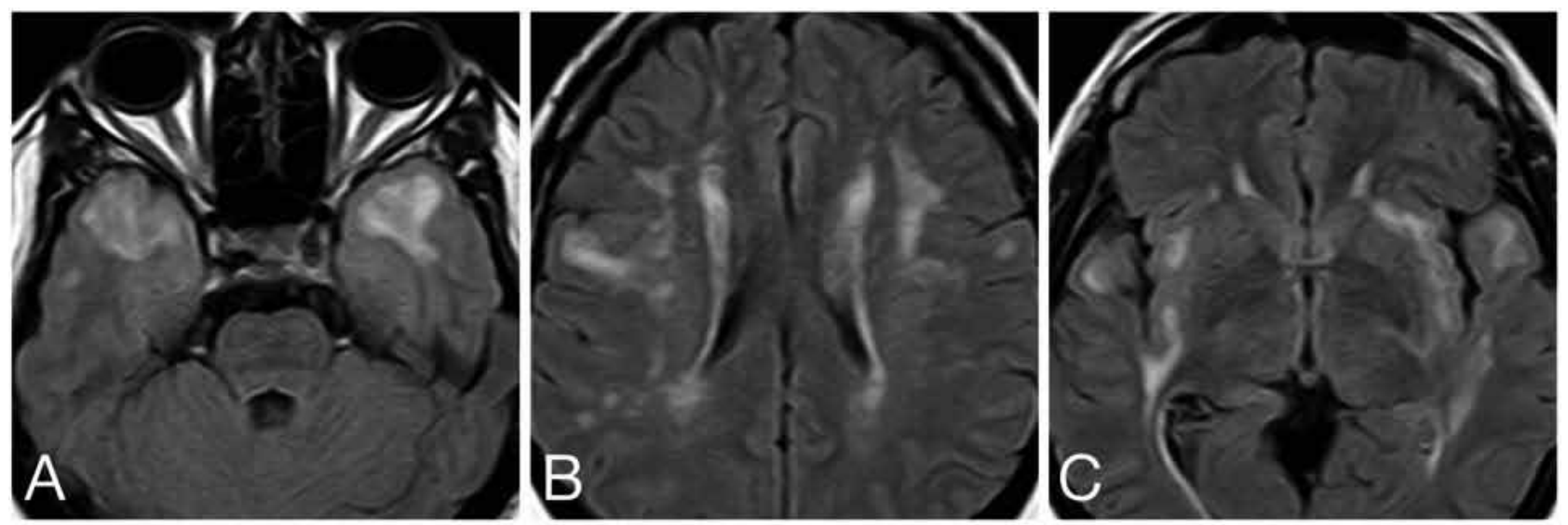

Figura 8: CADASIL - RM. FLAIR axiales a distintos niveles (a-c) donde se muestran lesiones confluentes de sustancia blanca, con respeto de fibras $U$ y compromiso marcado de polos temporales y cápsulas externas.

neuroprotección. Imagenológicamente puede parecerse a la distrofia miotónica tipo 1 o enfermedad de Steinert, sin embargo, la presentación clínica y ciertas características en imágenes, como respeto de tálamo y ganglios de la base, prominente atrofia cerebral, ausencia de infartos lacunares y atrofia de los grupos musculares visibles, más notorio en la musculatura masticatoria, permiten su diferenciación ${ }^{(11,13)}$.

Síndrome de Susac. Corresponde a una endoteliopatía autoinmune que se presenta con la tríada clásica de obstrucción de arteria retinal, hipoacusia sensorioneural y encefalopatía, esta última con un gran espectro de síntomas, que incluye confusión, alteraciones conductuales, fallas de memoria, ataxia, cefalea y psicosis. Se presenta usualmente en mujeres entre 20 y 40 años. Los hallazgos en el fondo de ojo son típicos. El tratamiento es una combinación variable de corticoides y otros inmunosupresores, y el pronóstico va a depender de la presencia de encefalopatía y de un diagnóstico y tratamiento precoz, pudiendo remitir en forma completa ${ }^{(14)}$. En RM los hallazgos son característicos, observando múltiples lesiones de sustancia blanca con predilección por el cuerpo calloso, con respeto relativo de la interfase callososeptal, con aspecto de "bola de nieve", las que presentan restricción en difusión (Figura 9). Además, pueden observarse focos de restricción en "collar de perlas" en la cápsula interna, lesiones en cerebelo y tronco, y refuerzo leptomeníngeo (Figura 9c). Los focos de alteración de señal pueden presentar realce con gadolinio en etapas agudas ${ }^{(15,16)}$.

CLIPPERS. Acrónimo inglés para Inflamación linfocítica crónica con realce pontino perivascular que responde a corticoides. Corresponde a una enfermedad inflamatoria poco frecuente y recientemente descrita caracterizada por infiltración inflamatoria perivascular de linfocitos $T$ de predominio pontino, de fisiopatología poco comprendida y sin una historia natural clara. Tiene una presentación clínica variable, pero en general subaguda con curso de recaídas y
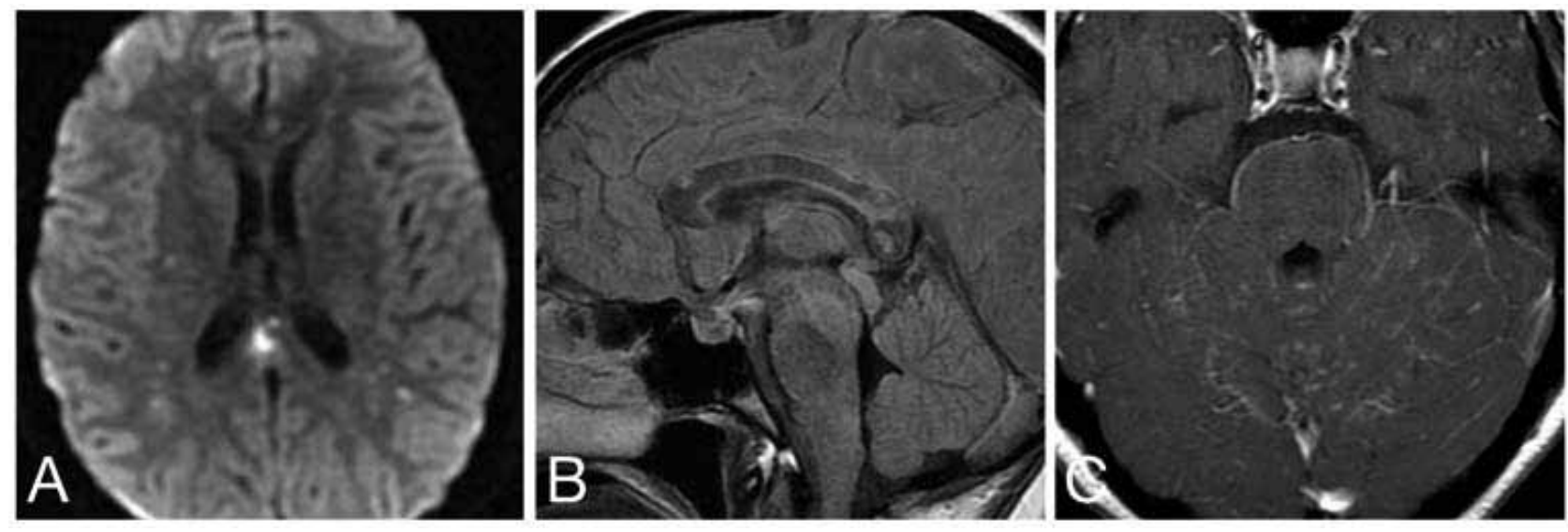

Figura 9: Síndrome de Susac - RM. Difusión isotrópica b=1000 axial (a) y FLAIR sagital (b) donde se observan lesiones en "bola de nieve" en el cuerpo calloso con afectación de cuerpo y esplenio y respeto relativo de la interfase calloso septal, además de lesiones subcorticales. En T1 post gadolinio (c) se identifica refuerzo leptomeníngeo en fosa posterior. 
remisiones, presentando signos cerebelosos y disfunción de nervios craneanos. La apariencia es típica, con múltiples focos de hiperintensidad en T2/FLAIR con realce parcheado o puntiforme con gadolinio en el puente, pero con extensión variable a estructuras adyacentes, por ejemplo el cerebelo (Figura 10). Presenta poco edema y efecto de masa ${ }^{(17)}$. El diagnóstico diferencial es extenso e incluye vasculitis del sistema nervioso central, varios tipos de encefalitis, linfoma y neurosarcoidosis ${ }^{(18,19)}$.

\section{Encefalomielitis diseminada aguda (ADEM)}

Corresponde a una enfermedad inflamatoria desmielinizante multifocal del sistema nervioso central, de curso agudo y monofásico en la gran mayoría de los casos, que ocurre predominantemente en niños, aunque también en adultos jóvenes. Puede estar precedida por una infección viral o administración de vacuna y tiene un pronóstico variable, la mayoría autolimitado con recuperación completa, no obstante con una mortalidad de hasta $10-20 \%$ en agudo, sobre todo considerando su variante necrohemorrágica de Weston Hurst. Clínicamente tiene un gran espectro de manifestaciones clínicas, entre las que destaca encefalopatía con grados variables de severidad, pudiendo presentar además hemiparesia, ataxia, parálisis de nervios craneanos, convulsiones, neuritis óptica bilateral, mielopatía, signos meníngeos y fiebre. Las alteraciones del líquido cefalorraquídeo son inespecíficas, incluyendo pleocitosis linfocítica ${ }^{(20)}$. En RM, las lesiones son múltiples, bilaterales y pueden comprometer encéfalo y médula espinal. Característicamente existe compromiso de sustancia blanca y gris, típicamente sustancia gris profunda incluyendo el tálamo. Además, puede haber compromiso subcortical y de fibras U. En casos más severos puede identificarse un componente hemorrágico en las lesiones. El compromiso de médula espinal se observa en aproximadamente un tercio de los casos, con lesiones confluentes y edematosas similar a una mielitis transversa. Existen características clínicas e imagenológicas de ADEM que permiten hacer la distinción con EM, dentro de las primeras se encuentra la edad de presentación predominantemente en población pediátrica, presencia de encefalopatía, convulsiones y meningismo, y una evolución monofásica con remisión completa. En imágenes permiten hacer la distinción la morfología de las lesiones, más grandes, redondeadas y peor definidas en el caso de ADEM, la presencia de compromiso talámico y de ganglios de la base, y la extensión del compromiso medular, entre otros (Figura 11). En caso de comprometer el cuerpo calloso, suele respetar la interfase callososeptal ${ }^{(21)}$. Sin embargo, sólo el seguimiento clínico y radiológico lograrán diferenciar ambas patologías en forma prospectiva y en adultos la probabilidad de convertir a esclerosis multiple es alta.

\section{Neuromielitis óptica (NMO)}

Corresponde a una enfermedad inflamatoria desmielinizante cuya etiopatogenia autoinmune ha sido recientemente descrita, con el descubrimiento de anticuerpos anti acuaporina 4 (AQP4) de tipo IgG, con un espectro de manifestaciones clínicas e imagenológicas ${ }^{(22)}$. La AQP4 es una proteína transmembrana que facilita el movimiento de agua, se expresa predominantemente en astrocitos y se encuentra en abundancia en el nervio óptico y quiasma,
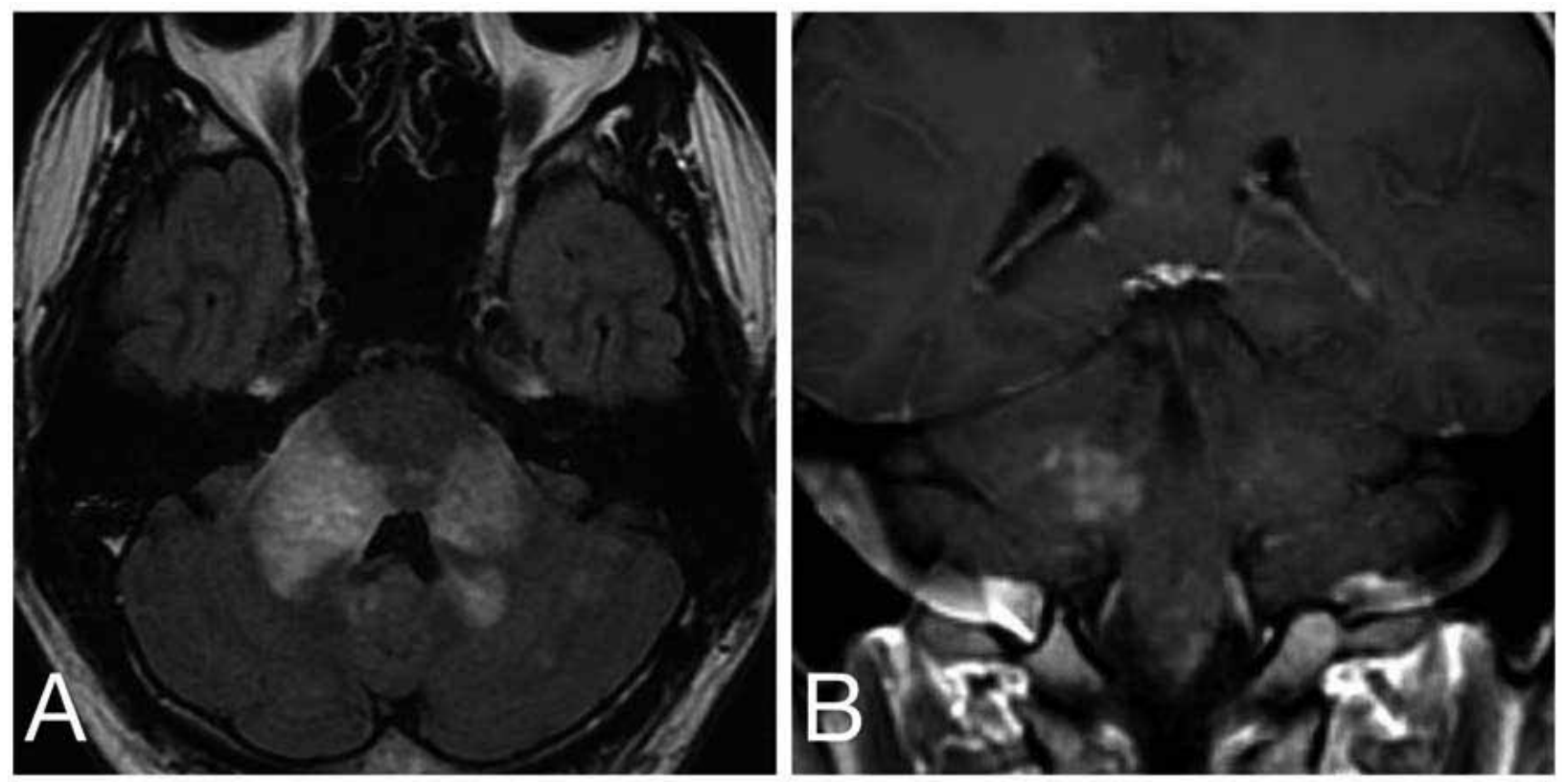

Figura 10: CLIPPERS - RM. FLAIR axial (a) y T1 con gadolinio coronal (b) donde se observan focos de alteración de señal en puente, pedúnculos cerebelos medios y cerebelo con realce parchado con contraste. 

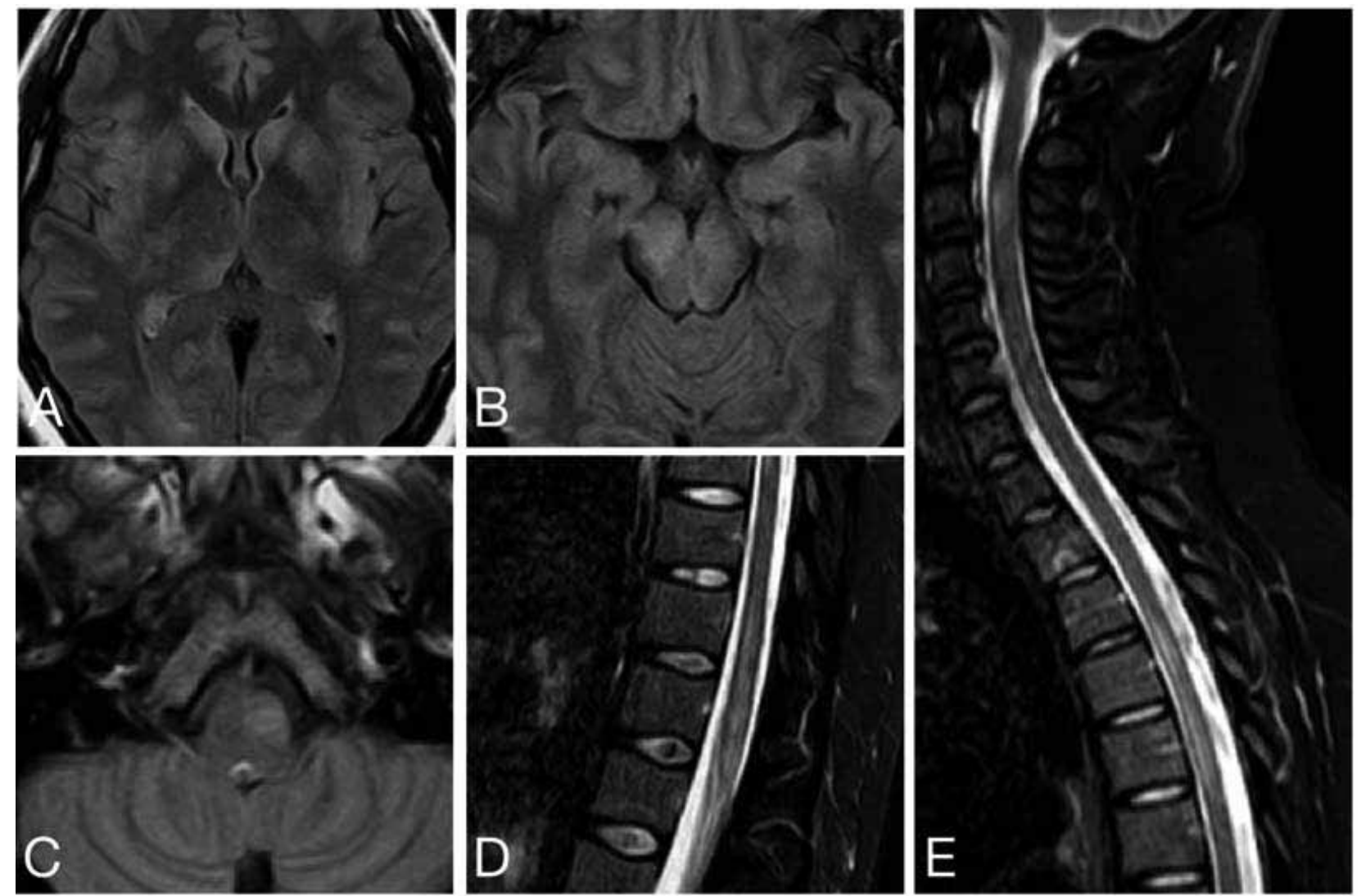

Figura 11: ADEM - RM. FLAIR axiales (a-c) donde se observan múltiples focos de hiperintensidad de señal en cuerpos estriados, pedúnculos cerebelosos, tálamo derecho y bulbo lateralizado a izquierda. T2 sagitales de médula cervicodorsal (d-e) donde son visibles múltiples lesiones hiperintensas de extensión variable en médula cervicodorsal, algunas de más de dos cuerpos vertebrales de extensión longitudinal.

hipotálamo, superficies periependimarias incluyendo la región diencefálica alrededor del tercer ventrículo, área periacueductal, el órgano circumventricular, que incluye el área postrema en el tronco, y la médula espinal $^{(23)}$. Las manifestaciones clínicas tienen relación con los sitios de compromiso, destacando la neuritis óptica bilateral a diferencia de EM, mielitis aguda habitualmente longitudinalmente extensas, náuseas y vómitos en el caso de un síndrome de área postrema y narcolepsia y anorexia en el caso de compromiso diencefálico. Las imágenes pueden mostrar alteraciones de señal en perfecta correlación con los sitios de expresión de AQP4 (Figura 12). El compromiso medular es típicamente mayor a 3 segmentos en el eje longitudinal y mayor al $50 \%$ en el plano transversal (Figura 13)(24), aunque puede ser corto, con preferencia de la sustancia gris adyacente al canal central, lo que permite distinguirla de EM. Otra característica que podría permitir su diferenciación es la presencia de focos más hiperintensos en T2 en el espesor del área de mielitis, lo que se ha denominado como lesiones moteadas brillantes ("bright spotty lesions" BSL) (Figura 13b) (25,26). La presencia de lesiones lineales bulbares o medulares periependimarias predice el desarrollo de lesiones longitudinalmente extensas ${ }^{(27)}$. Actualmente los criterios diagnósticos incluyen la RM, especialmente cuando los anticuerpos anti AQP4 son negativos o no están disponibles (Tabla 2).

\section{Neuropatía Óptica Isquémica}

Un diagnóstico diferencial importante a considerar es la neuropatía óptica isquémica (NOI). Se presenta con pérdida de visión monocular de instalación súbita y no presenta tratamiento efectivo en la actualidad. En general no es un dilema diagnóstico cuando son NOls anteriores, pero las NOls posteriores presentan síntomas más variables, y es en esos casos en que la RM puede ayudar al diagnóstico. Si bien en secuencias convencionales podría no presentar mayores alteraciones o hiperintensidad en secuencias con TR largo, el elemento característico y que permite su distinción con otras patologías que provocan neuritis óptica, por ejemplo EM, es la restricción a la difusión en el nervio óptico comprometido y la menor frecuencia de realce con gadolinio (Figura 14) ${ }^{(28,29)}$. Esto debe ser tomado en cuenta en el contexto clínico, ya que otras causas de restricción a la difusión 


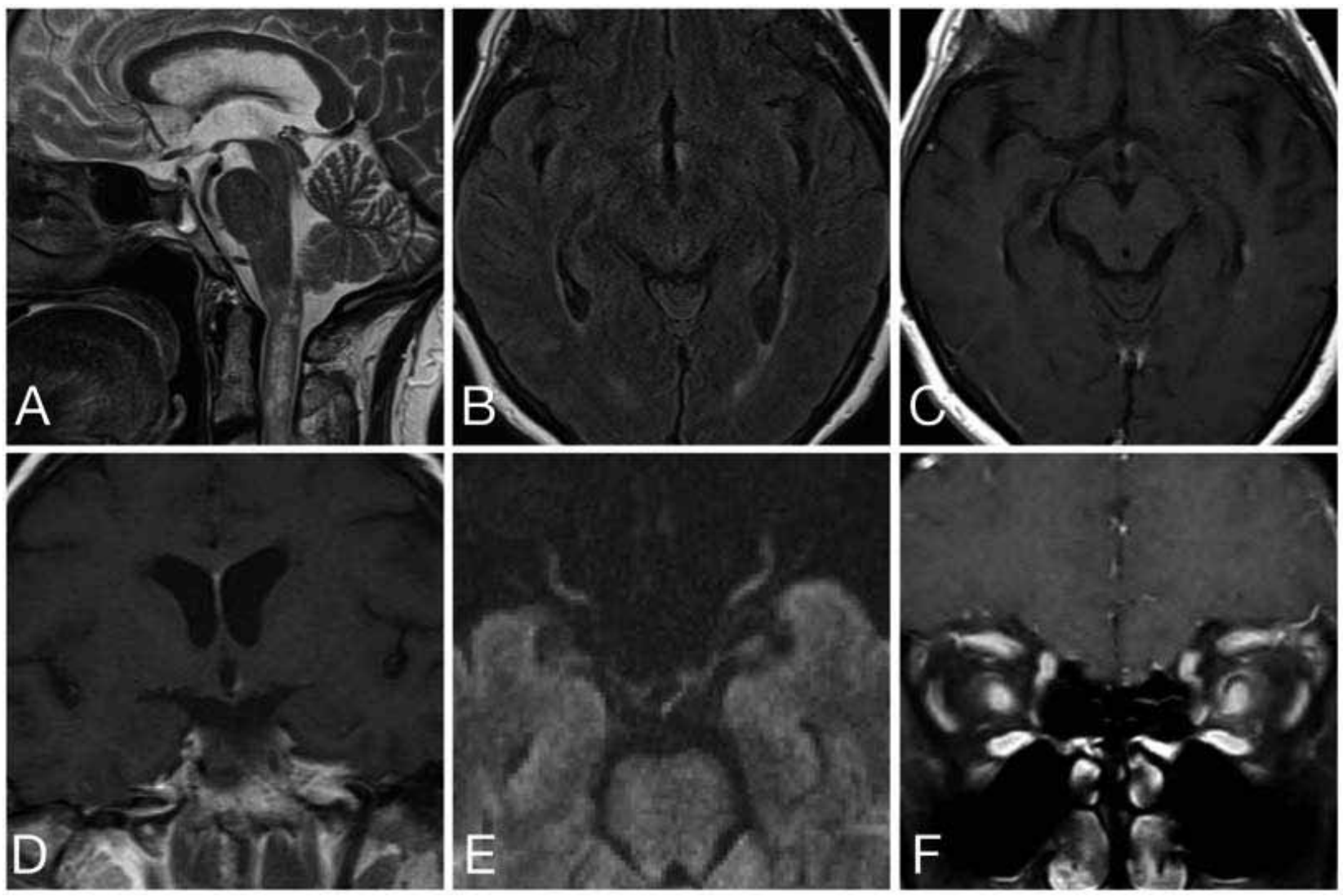

Figura 12: Neuromielitis óptica - RM. T2 sagital (a), FLAIR axial (b) y T1 con gadolinio axial (c) y coronal (d) donde se observan compromiso típico bulbar y medular que incluye el área postrema (a), y compromiso periependimario en ventrículos laterales y tercer ventrículo (b) con focos de realce con contraste. Difusión isotrópica b=1000 axial (e) y T1 con saturación grasa y gadolinio coronal (f) donde se observa alteración de señal y realce de ambos nervios ópticos, que incluye sus vainas y tejido adiposo adyacente.
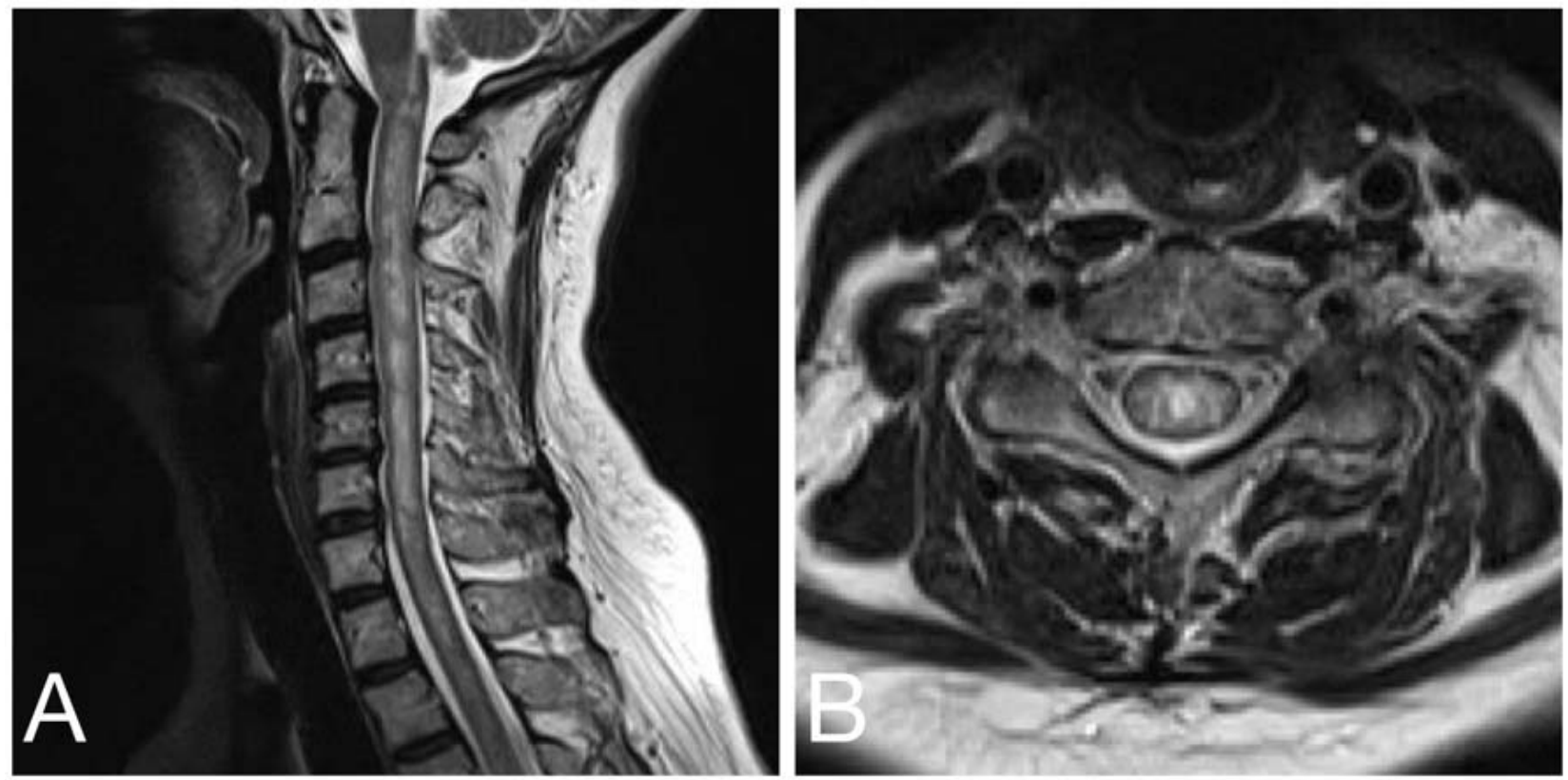

Figura 13: Compromiso medular en neuromielitis óptica - RM. T2 sagital (a) y axial (b) donde se observa compromiso longitudinalmente y transversalmente extenso, que permite la distinción con EM. En la imagen axial puede observarse un foco central de mayor señal en T2, lo que se ha denominado bright spotty lesion. 
en el nervio óptico incluyen trauma y tromboflebitis del seno cavernoso. Además, cuadros como sinusitis fúngica invasiva pueden complicarse con neuropatía óptica isquémica.

\section{Enfermedades vasculares de la médula espinal}

Como se mencionó anteriormente, el compromiso por EM de la médula espinal típicamente es corto en el eje longitudinal y parcial en el plano transversal. Existen patologías vasculares de la médula espinal que pueden dar alteraciones de señal que simulan enfermedad inflamatoria, entre ellos la isquemia medular y los shunts arteriovenosos espinales.

Isquemia medular. La isquemia medular es una enfermedad poco frecuente, que corresponde a menos del $1 \%$ de todos los accidentes vasculares. Puede presentarse como complicación en cirugías cardiovasculares u obedecer a otros factores de riesgo cardiovascular. En $25 \%$ de los casos no se logra documentar un origen. Dentro de las 12 a 15 primeras horas la RM puede no mostrar mayores alteraciones en sus secuencias habituales, no obstante, se observa restricción en difusión precozmente en el curso de la enfermedad, por lo que ante la sospecha debe incluirse en el protocolo, o bien repetir las secuencias 12 horas después. El cuadro clínico y las alteraciones en imágenes van a depender del territorio comprometido, siendo el más frecuente el de arteria espinal anterior con compromiso bilateral anterior y central (Figura 15) ${ }^{(30)}$. La diferenciación con una mielitis inflamatoria o viral en ciertos casos solo se podrá realizar por la presentación clínica, en especial con los cuadros tipo poliomielitis causados por enteroviruses, cuyas alteraciones en imágenes pueden ser idénticas a las de una isquemia medular. Cuando el nadir de los síntomas se alcanza antes de las 6 hrs, es compatible con isquemia medular.

Shunts arteriovenosos espinales. Los shunts arteriovenosos espinales, entre ellas las fístulas arteriovenosas durales o piales determinadas por conexiones anormales entre arterias y venas radiculares o medulares respectivamente, provocan congestión medular que se presenta con alteraciones de señal que pueden simular una mielitis. No obstante, existen varias claves imagenológicas para distinguirlas. El compromiso es en general extenso, con edema medular que se manifiesta como aumento de volumen y señal en T2, pudiendo presentar un realce heterogéneo con contraste. Son visibles múltiples vacíos de flujo perimedulares, que se corresponden con pequeñas estructuras vasculares en secuencias contrastadas determinadas por las venas dilatadas (Figura 16). La angiografía por sustracción digital permite la confirmación diagnóstica de un shunt arteriovenoso y la diferenciación entre una fístula dural y una fistula pial dorsal, que pueden ser indiferenciables en estudios no invasivos $^{(31)}$. Las fístulas durales espinales usualmente tienen una evolución larvada de semanas a meses, por lo que suelen plantear un dilema de diagnóstico clínico más que imagenológico, principalmente con
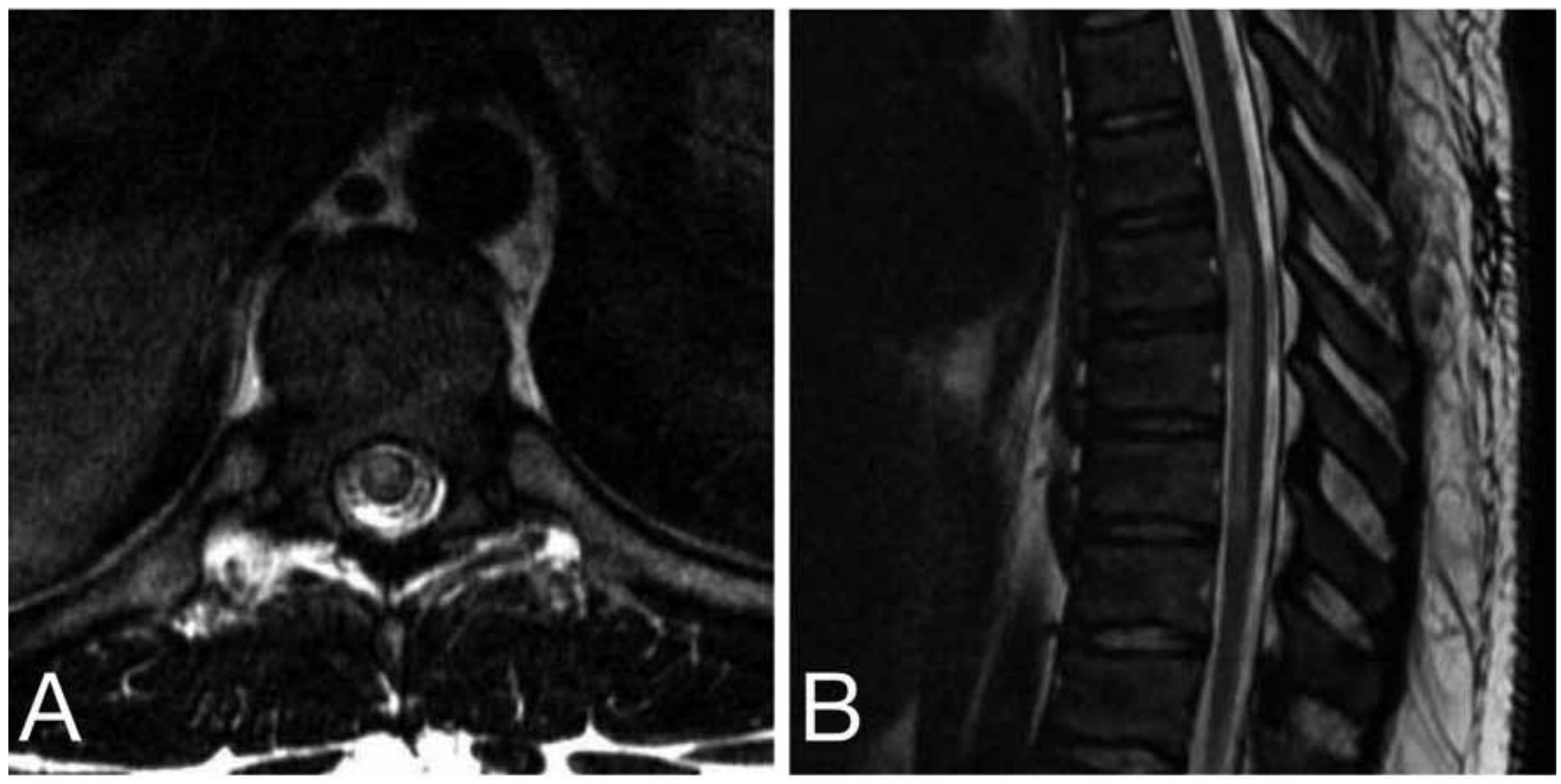

Figura 15: Isquemia medular - RM. T2 axial (a) y sagital (b) donde se observa hiperintensidad de señal en un segmento largo de la médula torácica, en su aspecto anterior. 

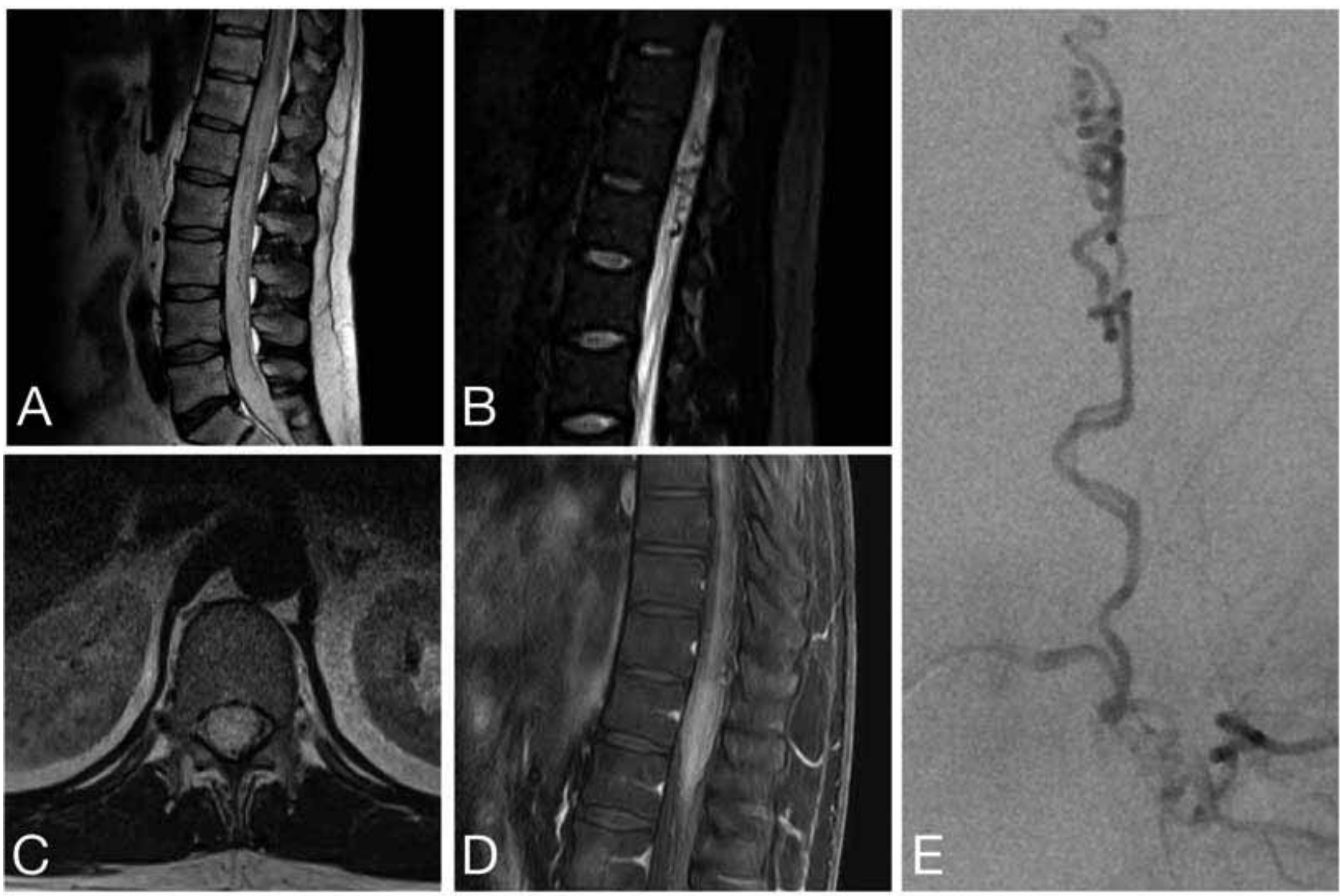

Figura 16: Fístula dural - RM. T2 sagital (a), STIR sagital (b), T2 axial (c) y T1 con saturación grasa y contraste sagital (d) donde se observa extenso edema medular $(a, c)$ con vacíos de señal perimedulares (b,c) que corresponden a venas dilatadas, con realce medular heterogéneo y opacificación de estas estructuras vasculares (d). Angiografía por sustracción digital (e) confirma el diagnóstico.

cuadros como la EM Primaria Progresiva.

\section{Conclusión}

La EM constituye un escenario frecuente en la práctica radiológica habitual y la RM juega un rol fundamental en su diagnóstico y seguimiento. Es posible encontrar hallazgos típicos tanto en estudios de encéfalo como en médula espinal. No obstante, en el diagnóstico diferencial clínico e imagenológico se encuentran varias enfermedades de sustancia blanca que pueden simular una EM y, de similar manera, existen variantes menos frecuentes de EM que podrían simular otras condiciones. Es fundamental entonces conocer hallazgos específicos que permitan orientar el diagnóstico diferencial en cada uno de los casos, lo que tiene implicancias directas en el manejo de estos pacientes.

\section{Declaración de conflictos de interés}

Declaro no poseer conflictos de interés.

\section{Referencias}

1. Reich DS, Lucchinetti CF, Calabresi PA. Multiple Sclerosis. Longo DL, editor. N Engl J Med. 11 de enero de 2018; 378(2): 169-80.
2. Lövblad K-O, Anzalone N, Dörfler A, Essig M, Hurwitz $B$, Kappos $L$, et al. MR imaging in multiple sclerosis: review and recommendations for current practice. AJNR Am J Neuroradiol. 1 de junio de 2010; 31(6): 983-989.

3. Thompson AJ, Banwell BL, Barkhof F, Carroll WM, Coetzee T, Comi G, et al. Diagnosis of multiple sclerosis: 2017 revisions of the McDonald criteria. Lancet Neurol. 2018; 17(2): 162-173.

4. Brownlee WJ, Hardy TA, Fazekas F, Miller DH. Diagnosis of multiple sclerosis: progress and challenges. Lancet. 2017; 389(10076): 1336-1346.

5. Ge Y. Multiple Sclerosis: The Role of MR Imaging. Am J Neuroradiol. 2006; 27(6): 1165-1176.

6. Filippi M, Rocca MA. MR Imaging of Multiple Sclerosis. Radiology. junio de 2011; 259(3): 659-681.

7. Karussis D. The diagnosis of multiple sclerosis and the various related demyelinating syndromes: A critical review. J Autoimmun. 2014; 48-49: 134-142.

8. Given CA, Stevens BS, Lee C. The MRI Appearance of Tumefactive Demyelinating Lesions. Am J Roentgenol. 23 de enero de 2004; 182(1): 195-199.

9. Hardy TA, Reddel SW, Barnett MH, Palace J, Lucchinetti CF, Weinshenker BG. Atypical inflammatory demyelinating syndromes of the CNS. Lancet Neurol. 2016; 15(9): 967-081. 
10. Hardy TA, Miller DH. Baló's concentric sclerosis. Lancet Neurol. 2014; 13(7): 740-746.

11. Kanekar S, Devgun P. A Pattern Approach to Focal White Matter Hyperintensities on Magnetic Resonance Imaging. Radiol Clin North Am. 2014; 52(2): 241-261.

12. Markus HS, Martin RJ, Simpson MA, Dong YB, Ali N, Crosby $\mathrm{AH}$, et al. Diagnostic strategies in CADASIL. Neurology. 22 de octubre de 2002; 59(8): 1134-1138.

13. Stojanov D, Vojinovic S, Aracki-Trenkic A, Tasic A, Benedeto-Stojanov D, Ljubisavljevic S, et al. Imaging characteristics of cerebral autosomal dominant arteriopathy with subcortical infarcts and leucoencephalopathy (CADASIL). Bosn J basic Med Sci. 9 de febrero de 2015; 15(1): 1-8.

14. Rennebohm RM, Susac JO. Treatment of Susac's syndrome. J Neurol Sci. 2007; 257: 215-220.

15. Greco A, De Virgilio A, Gallo A, Fusconi M, Turchetta R, Tombolini M, et al. Susac's syndrome - Pathogenesis, clinical variants and treatment approaches. Autoimmun Rev. 2014; 13(8): 814-821.

16. Vodopivec I, Prasad S. Treatment of Susac Syndrome. Curr Treat Options Neurol. 2016; 18(1): 1-8.

17. Dudesek A, Rimmele F, Tesar S, Kolbaske S, Rommer PS, Benecke R, et al. CLIPPERS: Chronic lymphocytic inflammation with pontine perivascular enhancement responsive to steroids. Review of an increasingly recognized entity within the spectrum of inflammatory central nervous system disorders. Clin Exp Immunol. 2014; 175(3): 385-396.

18. Pittock SJ, Debruyne J, Krecke KN, Giannini C, van den Ameele J, De Herdt V, et al. Chronic lymphocytic inflammation with pontine perivascular enhancement responsive to steroids (CLIPPERS). Brain. 1 de septiembre de 2010; 133(9): 2626-2634.

19. Pruitt AA. Infections of the cerebellum. Neurol Clin. 2014; 32(4): 1117-1131.

20. Graus F, Titulaer MJ, Balu R, Benseler S, Bien CG, Cellucci T, et al. A clinical approach to diagnosis of autoimmune encephalitis. Lancet Neurol. 1 de abril de 2016; 15(4): 391-404.

21. Sarbu N, Shih RY, Jones R V., Horkayne-Szakaly I, Oleaga L, Smirniotopoulos JG. White Matter Diseases with Radiologic-Pathologic Correlation. RadioGraphics. 12 de septiembre de 2016; 36(5): 1426-1447.

22. Wingerchuk DM, Banwell B, Bennett JL, Cabre P, Carroll W, Chitnis T, et al. International consensus diagnostic criteria for neuromyelitis optica spectrum disorders. Neurology. 2015; 85(2): 177-189.

23. Dutra BG, José Da Rocha A, Nunes RH, Martins AC, Júnior M. Neuromyelitis Optica Spectrum Disorders: Spectrum of MR Imaging Findings and Their Differential Diagnosis. RadioGraphics. 2018; 38: 169-193.

24. Tackley G, Kuker W, Palace J. Magnetic resonance imaging in neuromyelitis optica. Mult Scler J. 2014; 20(9): 1153-1164.

25. Hyun JW, Kim SH, Jeong IH, Lee SH, Kim HJ. Bright spotty lesions on the spinal cord: An additional MRI indicator of neuromyelitis optica spectrum disorder? J Neurol Neurosurg Psychiatry. 2015; 86(11): 1280-1282.

26. Yonezu T, Ito S, Mori M, Ogawa Y, Makino T, Uzawa A, et al. Bright spotty lesions" on spinal magnetic resonance imaging differentiate neuromyelitis optica from multiple sclerosis. Mult Scler J. 2014; 20(3): 331-337.

27. Cai W, Tan S, Zhang L, Shan Y, Wang Y, Lin Y, et al. Linear lesions may assist early diagnosis of neuromyelitis optica and longitudinally extensive transverse myelitis, two subtypes of NMOSD. J Neurol Sci. 15 de enero de 2016; 360: 88-93.

28. Rizzo JF, Andreoli CM, Rabinov JD. Use of magnetic resonance imaging to differentiate optic neuritis and nonarteritic anterior ischemic optic neuropathy. Ophthalmology. 2002; 109(9): 1679-1684.

29. Al-Shafai LS, Mikulis DJ. Diffusion MR imaging in a case of acute ischemic optic neuropathy. Am J Neuroradiol. 2006; 27(2): 255-257.

30. Vargas MI, Gariani J, Sztajzel R, Barnaure-Nachbar I, Delattre BM, Lovblad KO, et al. Spinal Cord Ischemia: Practical Imaging Tips, Pearls, and Pitfalls. AJNR Am J Neuroradiol. 2015; 36: 825-830.

31. Jeng Y, Chen DY-T, Hsu H-L, Huang Y-L, Chen C-J, Tseng Y-C. Spinal Dural Arteriovenous Fistula: Imaging Features and Its Mimics. Korean J Radiol. 2015; 16(5): 11191131. 